\title{
Grapevine rootstocks can be a source of infection with non-regulated viruses
}

\author{
Emese Demian • Nikoletta Jaksa-Czotter • \\ Janos Molnar • Gabor E. Tusnady • Laszlo Kocsis • \\ Eva Varallyay (D)
}

Accepted: 29 January 2020 /Published online: 6 February 2020

(C) The Author(s) 2020

\begin{abstract}
Grapevine can be infected by several viruses and viroids, the presence of which can lead to yield losses and vineyard decline. Our previous survey of vineyards in Hungary suggested that viral infection originates from infected propagation material. To investigate whether rootstocks can be a source of virus infections, we surveyed seventeen rootstock vineyards and two rootstock collections in Hungary to determine the virome by high-throughput sequencing of small RNAs. The presence of the viruses was also tested by RT-PCR. The results showed that viruses whose presence is routinely checked were almost absent in rootstock vineyards but were present in rootstock genotype collections. Moreover, first the time in Hungary, we
\end{abstract}

Electronic supplementary material The online version of this article (https://doi.org/10.1007/s10658-020-01942-w) contains supplementary material, which is available to authorized users.

E. Demian $\cdot$ N. Jaksa-Czotter $\cdot$ E. Varallyay $(\square)$ Agricultural Biotechnology Research Institute, NARIC, Szent-Györgyi Albert Street 4, Gödöllő 2100, Hungary e-mail: varallyay.eva@abc.naik.hu

J. Molnar · G. E. Tusnady

Institute of Enzymology, Research Center of Natural Sciences, HAS, Budapest, Hungary

L. Kocsis

Department of Horticulture, Georgikon Faculty, University of Pannonia, Deák F Street 16, Keszthely 8360, Hungary

Present Address:

J. Molnar

Turbine Ltd., Bem József utca 9, Budapest 1027, Hungary detected the presence of Australian grapevine viroid in the rootstock genotype collection at Pecs. In contrast, viruses that are not regulated or not routinely tested, namely, grapevine rupestris stempitting-associated virus, grapevine Syrah virus-1 and grapevine Pinot gris virus, were detected in almost all locations in most of the varieties. The presence and absence of infected rootstock genotypes in the same vineyard together with phylogenetic analysis suggested that viral infections originated from infected propagation material. Moreover, we found the symptomatic variant of grapevine Pinot gris virus in several rootstock vineyards without symptoms, suggesting the possibility for leaf mottling and deformation disease symptoms to manifest on susceptible cultivars following grafting onto these rootstocks.

Keywords Grapevine · Rootstock · Viral diagnostics · Virus infection · Small RNA HTS · GPGV

\section{Introduction}

Grapevine is a perennial, woody plant established in vineyards that are maintained for decades. The lifespan of vineyards is based on their health, which decrease considerably with the presence of pathogens.

Grapevine rootstocks have been used since the end of the nineteenth century, when grape phylloxera appeared in Europe. A total of $20-25 \%$ of the "historical" vineyards of Hungary was 
reconstructed with grafted vines after the vineyard decline. While the most important property of the used rootstock is its resistance to phylloxera (even against the emerging aggressive biotypes), its features determine both the mineral and water uptake of the plant and the vigour of scion. Moreover, rootstock genotypes can influence the composition of bacterial communities in the root system, which could have an influence on the terroir characteristics of grapes (Marasco et al. 2018). Five rootstocks (SO4, 5BB, 110R, 1103P and 140Ru) are predominant worldwide (Ollat et al. 2016). Rootstock genotypes from Hungary, which are clones originally selected by Zsigmond Teleki from French seedling populations (Teleki 5C, TelekiFuhr SO4, Teleki-Kober 125 AA and TelekiKober 5BB), are among the most popular and widespread globally (Poczai et al. 2013) and are also very popular in Hungary. Georgikon 28, a rootstock bred in Keszthely by Karoly Bakonyi, is extensively used although Fercal, which originated from France (Laucou et al. 2008), is the most abundant rootstock on calcareous soil.

Grapevine, a host of more than 80 viruses (Martelli 2018), can be simultaneously infected by several viruses and viroids without showing apparent symptoms. The regulated viruses in Hungary are grapevine fanleaf virus (GFLV), Arabis mosaic virus (ArMV), grapevine fleck virus (GFkV), grapevine leafroll associated virus-1, 2, 3 (GLRaV-1, 2, 3), grapevine virus A (GVA) and grapevine virus $B(G V B)$. Latent infection, when virus concentration is low and below the detection threshold of traditional testing methods (ELISA and RT-PCR), or infections with untested viruses present in foundation vineyards at nurseries can both serve as a starting point for epidemics in young vineyards. High-throughput sequencing (HTS)-based metagenomics approaches can reveal the presence of all pathogens in a sample, even if the pathogens have not been reported from the investigated plant or have never been described (Massart et al. 2014; Roossinck et al. 2015; Boonham et al. 2014). Viral metagenomics studies have been proven also to be successful diagnostic methods and used for surveys to determine viromes of vineyards (Coetzee et al. 2010; Eichmeier et al. 2016; Czotter et al. 2018b).

In this study, we used small RNA HTS to investigate seventeen rootstock vineyards and two rootstock collections in order to elucidate their viral infection statuses to find out if they are clean from viruses or not.

\section{Materials and methods}

Plant material and sample preparation

Samples were collected from 17 Hungarian rootstock vineyards and two rootstock collections in July 2015. Seven to 18 randomly selected asymptomatic individuals, representing different genotypes were sampled per vineyard (twelve genotypes in total). We collected leaves (old and young) together with shoot tips, inflorescences and tendrils if it was possible. The 5BB samples from Beled were collected from forced twigs. In the rootstock collections, 34 plants from Pecs and 33 plants from Tarcal, one of each genotype, were sampled (see Supplementary Tables 1-3 for detailed information on the vineyards, varieties and sampling). We extracted RNA from leaves, shoot tips, tendrils and inflorescences by the CTAB method (Gambino et al. 2008). We made individual-plant RNA pools by mixing equal amounts of RNA from different organs. Pools, representing the vineyards (1-19) were prepared with the same strategy by mixing equal amounts of RNA from all of the sampled plants. Small RNA libraries were prepared using a TruSeq Small RNA Library Preparation Kit (Illumina) and our in-house-modified protocol (Czotter et al. 2018a). One sequencing library/plantation or collection were sequenced (19 in total) using a single index on a HiScanSQ by UD-Genomed (Debrecen, Hungary) (50bp, single-end sequencing, with 8 samples/sequencing lane). FASTQ files of the sequenced libraries have been deposited in the GEO and can be accessed through series accession number GSE130994.

Pipeline for data evaluation of hight throughput sequencing results (bioinformatics)

A total of 12.8-26.4 million raw reads were analysed by bioinformatics methods using the CLC Genomics Workbench (Qiagen) (Supplementary Table 6 and 7). Although small RNA HTS is an approved virus diagnostic method there is no standardized bioinformatic pipeline for its analysis. In our work we followed recommendations of our international survey on testing performance of different pipelines (Massart et al. 2019). This is why during virus diagnostics we searched for the presence of virus specific reads, checked the number of normalized virus specific reads, the presence of any virus specific contigs and calculated that how entirely the virus genome was covered by small RNA 
reads. After trimming and quality control, reads were used for de novo assembly (the embedded algorithm in CLC) to build longer contigs. Annotation of these contigs was performed using BLAST with the GenBank plant host virus reference collection. In parallel the reads were mapped to the reference genomes of grapevine infecting viruses and were counted with and without redundancy. The normalized redundant read count was calculated as reads/ 1 million sequenced reads, to be able to compare the results of the different libraries. Based on this mapping, a consensus sequence was generated using Geneious Prime software and used to calculate the percent $(\%)$ coverage of the viral genome. The presence of virus-specific contigs or coverage of the viral genome greater than $70 \%$ was set as a threshold for the presence of a specific virus.

\section{Virus diagnostics by RT-PCR}

Pooled RNA extracts representing each vineyard were used as templates for cDNA synthesis by a RevertAid First Strand cDNA Synthesis Kit (Thermo Fisher Scientific, USA) with random primers according to the manufacturer's instructions. The generated cDNA was used for PCRs (primers used to amplify viral parts are provided in Supplementary Table 4) performed with Phire Hot Start II DNA Polymerase (Thermo Fisher Scientific). For Sanger sequencing, we used cDNA synthesized from RNA pools of individuals as a template in the PCRs using Q5 Hot Start High-Fidelity DNA Polymerase (New England Biolabs, UK). PCR products were purified and sequenced, and sequences were deposited into GenBank (for GenBank accession numbers, see Supplementary Table S5 and the text).

\section{Sequence comparison}

For phylogenetic analysis of viral sequences, we used MEGA7 (Kumar et al. 2016). Phylogenetic relationship history was inferred using the neighbour-joining method (Saitou and Nei 1987). The percentage of replicate trees in which the associated taxa clustered together in the bootstrap test (500 replicates) is shown next to the branches of the phylogenetic trees (Felsenstein 1985). The evolutionary distances were computed using the Jukes-Cantor method (Jukes and Cantor 1969) and are presented as the number of base substitutions per site.

\section{Results and discussion}

Seventeen rootstock vineyards and two rootstock genotype collections in nine different vine-growing regions in Hungary were surveyed (Fig. 1 and Supplementary Table 1). Small RNA HTS was used to reveal any viral infections. To validate these results, we used RT-PCR and published diagnostic primers to test different rootstock genotypes or individual plants for the presence of a virus (Supplementary Figures and Table 1).

Rootstock vineyards are free from regulated viruses

The presence of regulated viruses is officially checked by DAS-ELISA regularly. Due to this regular monitoring, all of vineyards tested were free from regulated viruses in Hungary, except 10_V, 12_KSZ and 16_TC2, where GFkV was present (Table 1 ). RT-PCR confirmed results of the bioinformatics analyses (Supplementary Fig. 1 and Table 1). Discrepancies were found between HTS and RT-PCR results in some cases, but this could arise from the non-perfect bioinformatics analysis. For instance, in the absence of GFkV derived contig RT-PCR showed the presence of the virus in $10 \_$V and 12_KSZ. When we aligned small RNA reads of these libraries directly to the reference genome, we found $68-72 \%$ coverage, which could indicate infection by this virus. Testing different genotypes at these vineyards revealed that only one genotype represented by seven individuals in the pool (11 individuals in total) from 10_V 5BB and one genotype represented by eight individuals in the pool (17 individuals in total) from 12_KSZ 5C were infected with GFkV (Supplementary Fig. 2/a). RNA from the non-infected plants diluted the sample for virus derived small RNAs, and this is why the number of GFkV specific reads dropped below the threshold of our analysis. In 16_TC2 the rootstock varieties themselves ( $5 \mathrm{C}$, represented by seven individuals, and Ruggeri 140, represented by one individual) were free from this virus (Supplementary Fig. 2/a and b). The reason of the presence of GFkV derived contig was that in this library in addition to the rootstocks, RNA extracted from a symptomatic individual plant ("Harslevelu") was also included. According to the virus-specific RT-PCR, this plant was infected by GFkV, which is why GFkV-specific contigs were detected.

In rootstock collections, regular checks are not required by regulatory authorities. The collection from Pecs is approximately 20 years old and showed infection 


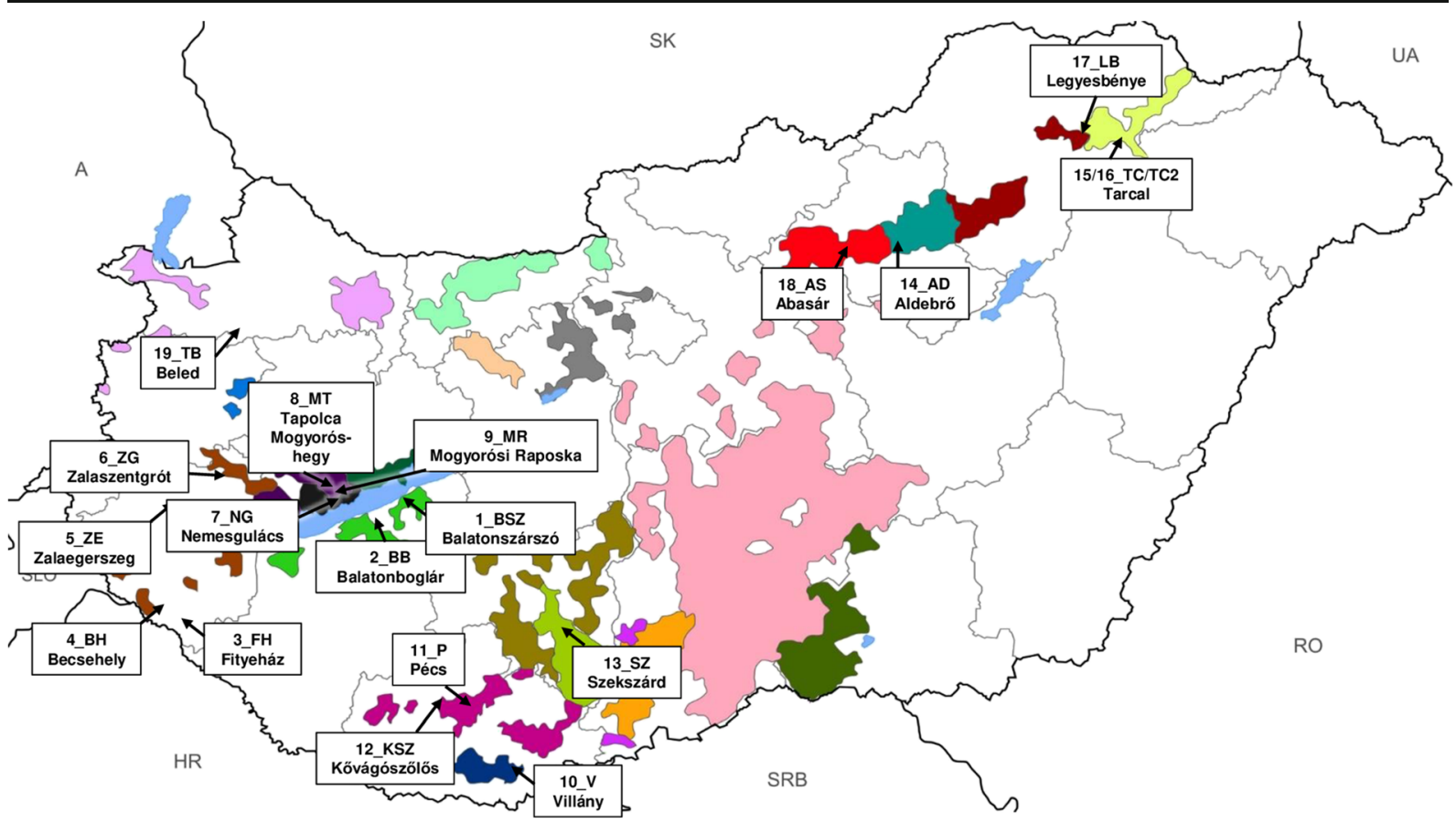

Fig. 1 Map of Hungarian vineyards indicating sampled rootstock vineyards with their library identification number

by GFLV, ArMV, GFkV and GLRaV-2 (Supplementary Table 7). In contrast, the collection from Tokaj is a young vineyard, only 2 years old, and showed only GFkV infection (Supplementary Table 7).

Results of RT-PCR showed the same results for GFLV (present in 13 of 34 individuals from Pecs), GFkV (present in 19 individuals from Pecs but only three of 33 individuals from Tokaj) and GLRaV-2 (present in three individuals from Pecs) (Supplementary Fig. 1 for the pools and Supplementary Fig. 3 for the individuals).

We also obtained ArMV-specific contigs from 11_P, but we could not amplify any part of the virus from the pool or from the individuals (Supplementary Fig. 1 and Supplementary Fig. 3/a lower panel). GFLV and ArMV are nepoviruses with high homology. The RNA1 and RNA2 in their reference genomes are both $72 \%$ identical. We reannotated ArMV annotated contigs of this library using BLAST from the NCBI and found that most of the contigs had higher identity with a GFLV variant (GFLV-GHu: EF426852.1) than with the ArMV reference genome (Supplementary Table 8). Interestingly, this accession originates from Hungary (Vigne et al. 2008) and was the subject of a case study of interspecies recombination within the RNA2 of GFLV and ArMV. To further investigate the reason for false-positive
ArMV detection, we remapped all of the ArMV RNA2 mapped small RNA reads. Out of 8599 small RNA reads 6161 could be mapped to the GFLV-GHu RNA2. Moreover, in this library, we identified contigs annotated as grapevine deformation virus (GDefV) (64 contigs as GDefV RNA1 and nine contigs as GDefV RNA2) (Supplementary Table 7). GDefV, similar to GFLV-GHu, is a recombinant of GFLV and ArMV (Elbeaino et al. 2012). This result suggests that in this collection, these or similar recombinants are present. RT-PCR of GFLV was positive only because at the primer annealing site, the sequence of the variant was more similar to that of GFLV than to that of ArMV. With this knowledge, we can state only that a recombinant nepovirus is present in this rootstock collection.

In the case of GLRaV-3, we faced the opposite problem. There was no GLRaV-3-specific contig present in 11_P, but the coverage of its genome was $87.1 \%$ (Supplementary Table 7), which usually coincides with the presence of the virus. During the GLRaV-3-specific RTPCR, we did not obtain any product when we used pooled RNA from the vineyard as a template (Supplementary Fig. 1). Testing individuals with the same method resulted in four positive samples (Supplementary Fig. 3/c lower panel). In this case, RNA from negative samples diluted the pool, which is why RT- 


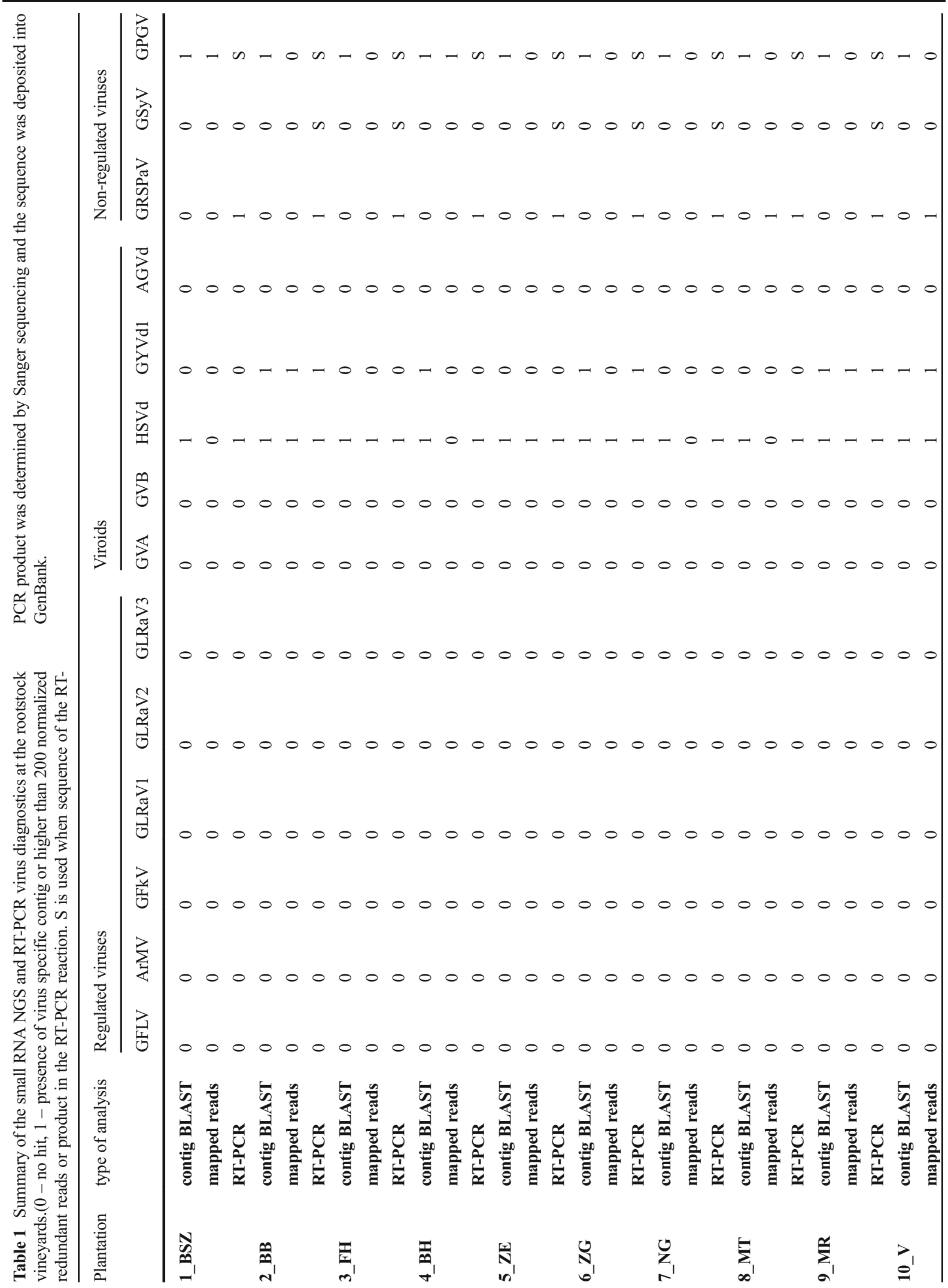




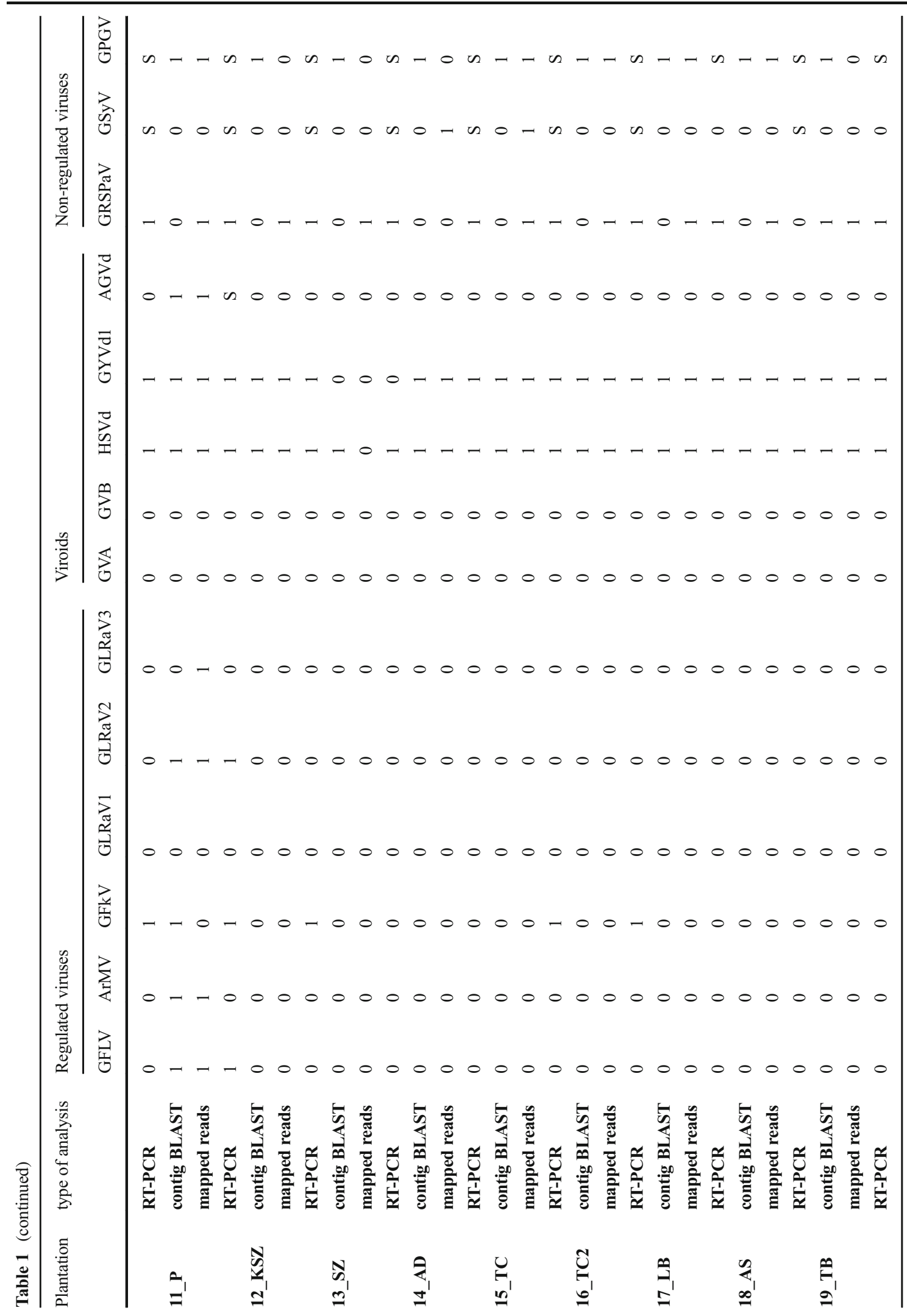


PCR showed a false-negative result when this pool was used as the template. However, small RNA HTS showed high coverage of the GLRaV-3 genome, suggesting the presence of this virus.

According to the above analysis rootstock vineyards in the country were free from regulated viruses. This shows that the use of regular tests, even with traditional, less sensitive methods, enables the maintenance of a virus-free status and that on-site infection is still very rare.

Viroids are present in the rootstocks

Bioinformatics analysis of the libraries showed that hop stunt viroid (HSVd) was present in all of the libraries (Supplementary Table 7). Although in some cases the normalized redundant read number was below our threshold (200), the coverage of the viroid genome was uniformly $100 \%$ and this can be a reason why we could detect it also with RT-PCR (Supplementary Fig. 4). Grapevine yellow speckle viroid-1 (GYSVd-1) was also regularly, but not ubiquitously, detected. In 1_BSZ, 3_FH, 5_ZE, 7_NG, 8_MT, and 13_SZ only coverage of the viroid genome was higher than $80 \%$, but neither contig nor high number of reads (more than 200 normalized redundant reads) indicated the presence of this viroid (Supplementary Table 7). RT-PCR for this viroid showed a similar pattern (Supplementary Fig. 4), and we could not detect a viroid specific product in the above samples. Moreover, we could not get a product in in 4_BH (Supplementary Fig. 4). Although in this library, we could detect one contig, the redundant read count was below 200, and the coverage was only 92\% (Supplementary Table 7). Another GYSVd variant may have been present in this sample what would explain this ambiguity, but verifying this assumption requires further investigation. In the rootstock collection from Pecs, we detected the presence of five Australian grapevine viroid (AGVd)-derived contigs. The number of normalized redundant read counts was greater than 200, and the coverage of the viroid was $100 \%$ (Supplementary Table 7). Moreover, we could amplify it by RT-PCR (Supplementary Fig. 4). When we tested the different varieties for the presence of AGVd we found it in two different 5BB accessions (Supplementary Fig. 5). Sequences of these two isolates proved to be identical (MK975820), and they were also identical to the consensus sequence generated from the small RNA reads. To the best of our knowledge, this is the first report of
AGVd from Hungary, but as it was only present in a collection it does not represent the presence of this viroid at the vineyards of the country. Unfortunately, we are not aware of the origin of these accessions, but phylogenetic analysis showed that the variant clustered with the Italian and Australian variants and was distantly related to the Asian and Tunisian variants (Gambino et al. 2014) (Fig. 2).

Our results show that grapevine rootstock vineyards are highly infected with viroids, a presence which is not regulated.

Rootstock vineyards are highly infected by non-regulated viruses

Bioinformatics analysis of the sequenced libraries revealed the presence of grapevine rupestris stem pittingassociated virus (GRSPaV) - (in 19-TB), grapevine Pinot gris virus (GPGV) - (in all of the libraries) and grapevine deformation virus (GDefV) specific (only in the collection at Pecs in 11_P) contigs (Supplementary Table 7). Moreover, we suspected the presence of grapevine Syrah virus-1 (GSyV-1), as it was found to be widespread in our previous survey of the vineyards in our country (Czotter et al. 2018b). GRSPaV-specific contigs were identified only in 19_TB, where we used forced twigs for RNA extraction which coincides with a positive RT-PCR (Supplementary Fig. 6). Moreover, virus-specific products appeared in all of the other samples except 18_AS. At the rootstock collections

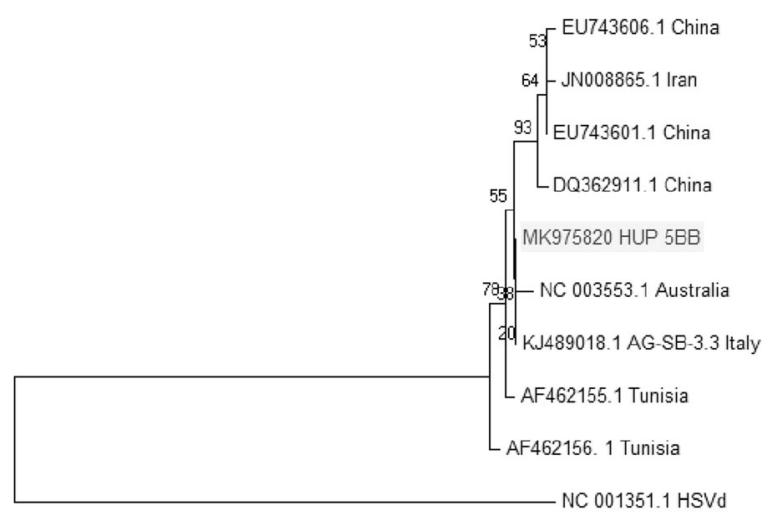

0.050

Fig. 2 Phylogenetic analysis of the AGVd sequenced at 11_P (MK975820). The tree was constructed using neighbour-joining method of MEGA7. Reference sequence of the hop stunt viroid was used to root the tree 
Fig. 3 Phylogenetic analysis of the GSyV-1 variants sequenced at different rootstock vineyards (MK975806 - MK975819), highlighted with blue colour. Green boxes show sequences originating from survey of vineyards of Hungary (Czotter et al. 2015). The tree was constructed using neighbourjoining method of MEGA7

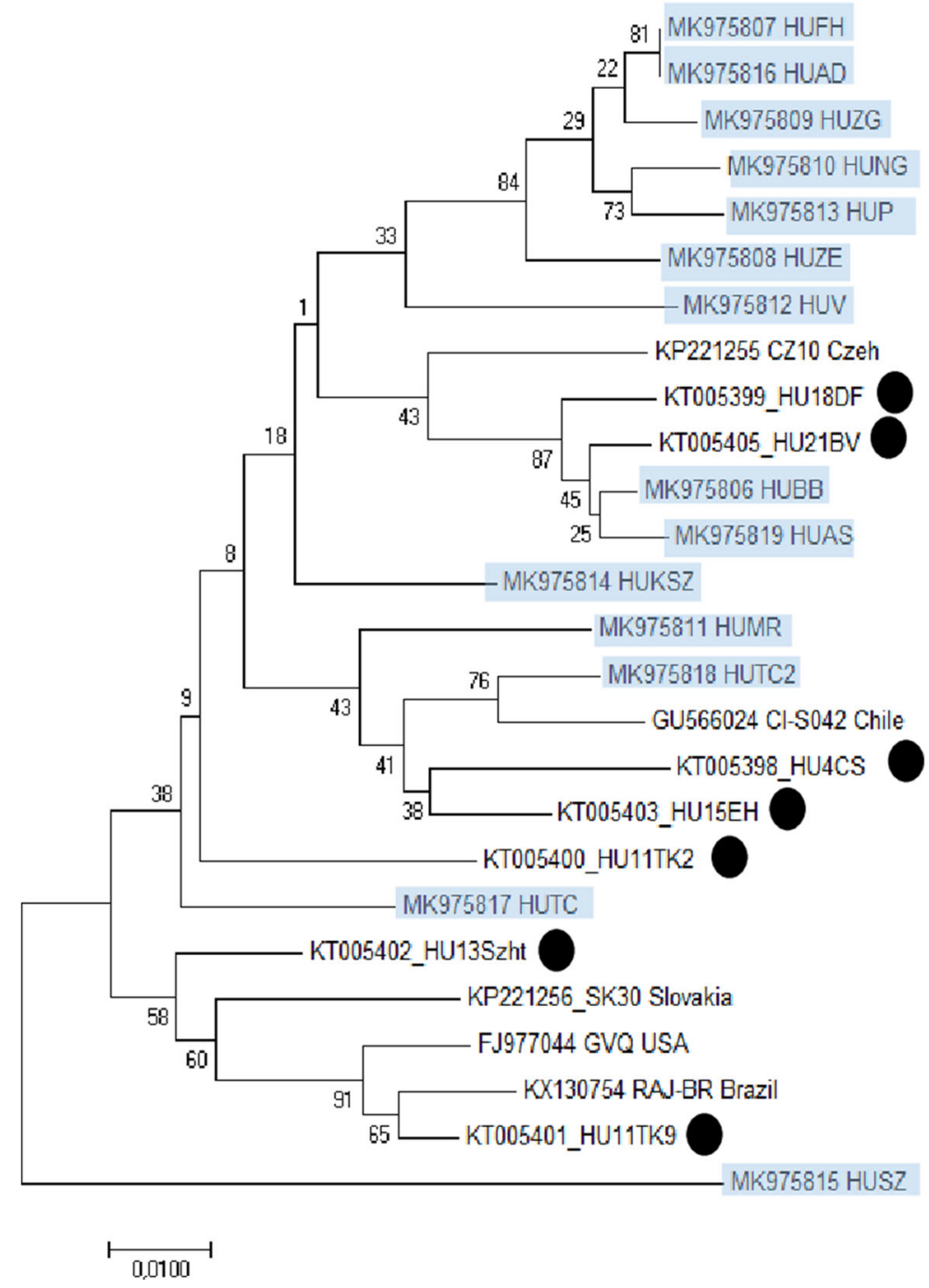

infection was detected also by high incidence (Supplementary Fig. 7).

In case of GRSPaV we previously found the same contradiction: positive RT-PCR in the lack of virus derived small RNAs, during our survey of Hungarian vineyards (Czotter et al. 2018b). We still do not know the reason for this discrepancy, but it could be both a technical problem or have a deeper biological reason. The presence of GRSPaV in rootstock varieties was investigated by Meng and colleagues (Meng et al. 2006). In addition to the high variability of GRSPaV, they found that while scions were usually infected by multiple strains of the virus, viral populations in the rootstocks were homogenous and contained only one strain. However, different rootstock varieties contained virus strains belonging to different clades. We sequenced pools of different plants representing different genotypes, possibly containing several different GRSPaV strains, which may have diluted the concentration of any particular strain. As a result, the concentration of strain specific GRSPaV-derived small RNAs could have been dropped below our detection threshold. On the other hand, during their long time of coexistence, grapevine and GRSPaV was shown to have mutual advantage which could be beneficial for both of them (Gambino et al. 2012). This could lead to the decreased activity of antiviral silencing which can explain why we could detect the virus but not the virus derived small RNAs. At this point we can only state that the grapevine rootstock vineyards are infected with this virus. 


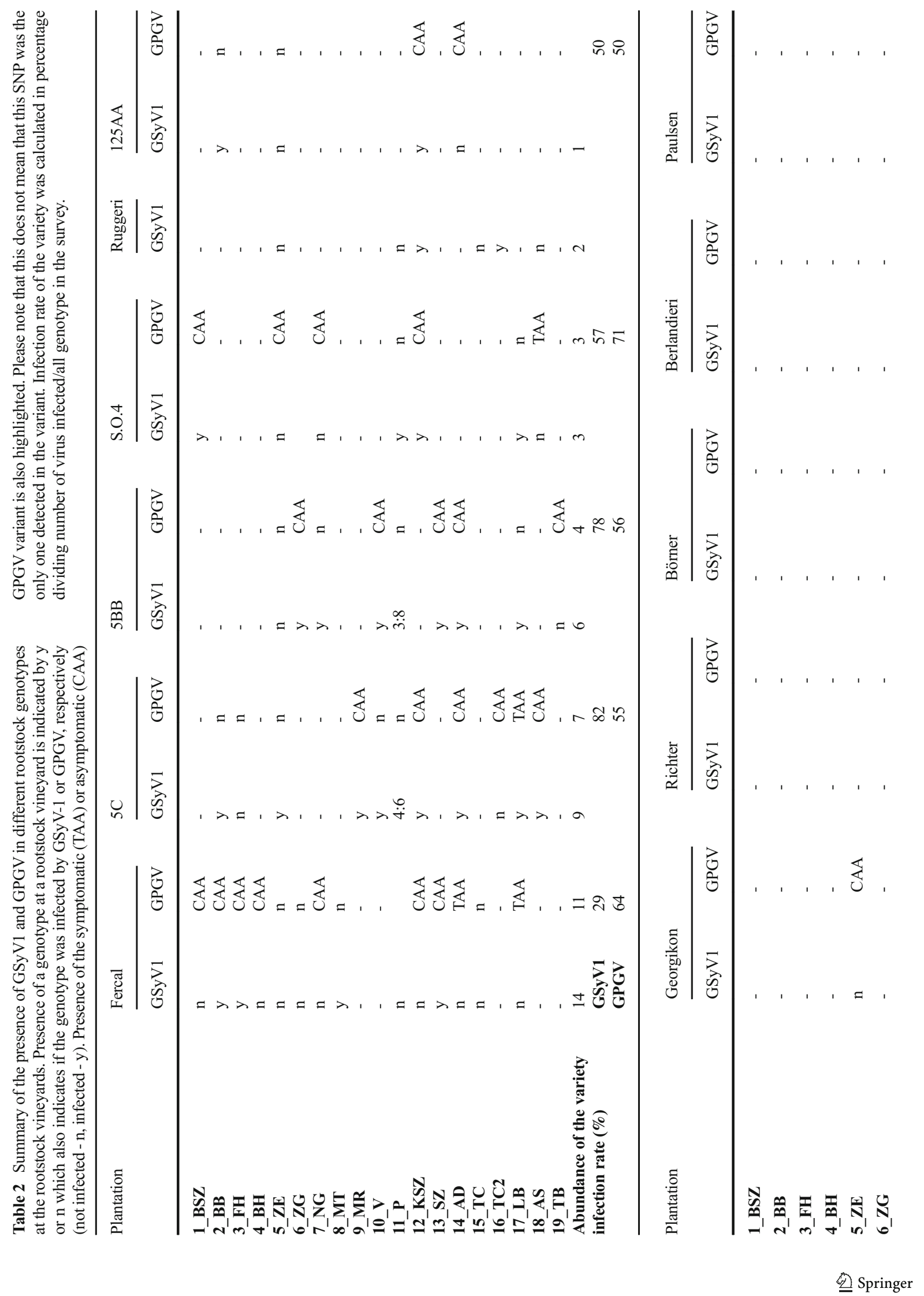




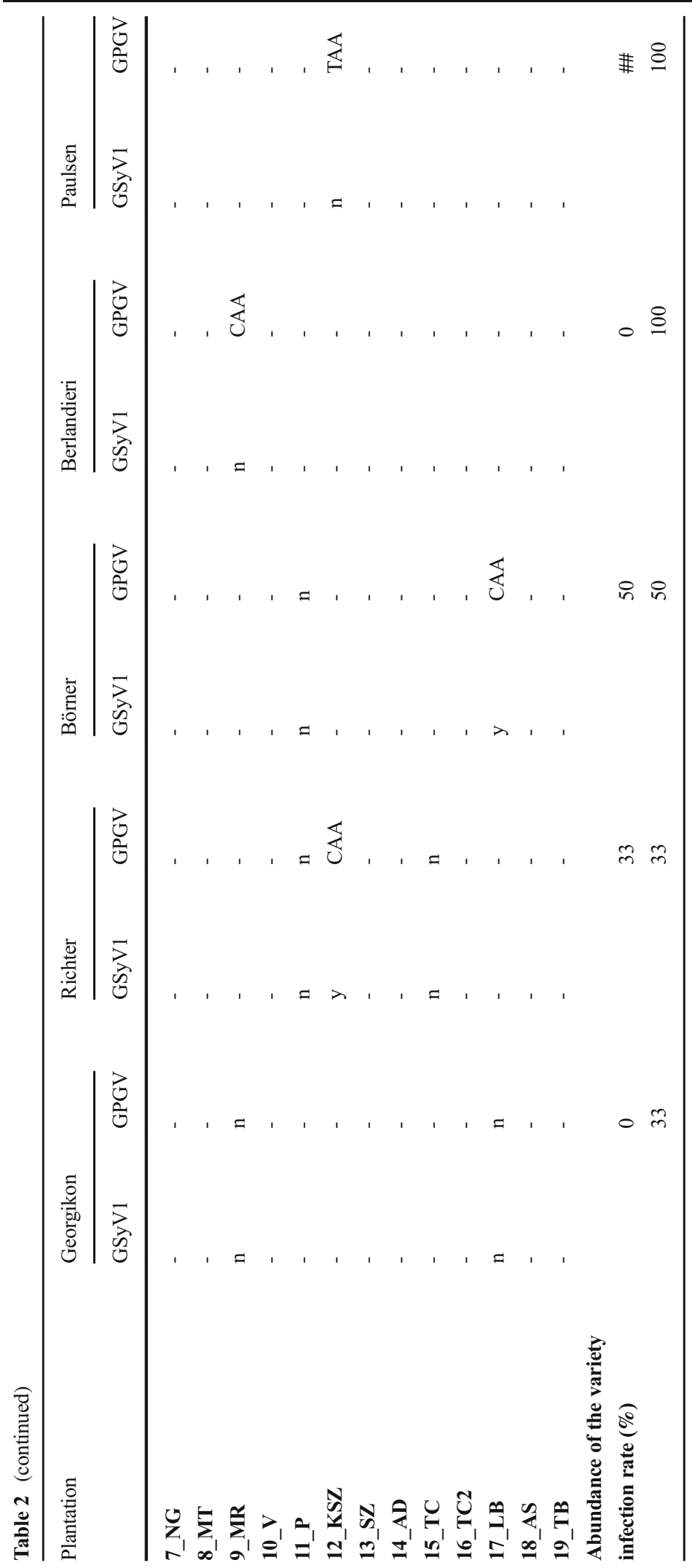




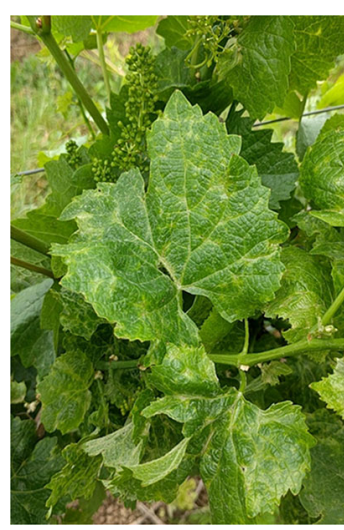

Fig. 4 Pinot gris plant at Csokako showing GLMD and is infected with the symptomatic variant of GPGV

Resolving the above contradiction is beyond our survey and needs further investigation in the future.

Although we did not find any GSyV-1-specific contigs when we used the reference genome during our BLAST search, we found greater than $70 \%$ coverage of the GSyV-1 genome in four libraries (in 10_V and 14_AD and in both rootstock collections), indicating its presence (Supplementary Table 7). It was previously reported that European GSyV-1 isolates were more divergent from the reference genome described in California than the American ones (Glasa et al. 2015). Therefore, we annotated our contigs again by a BLAST search using the European SK30 isolate of GSyV-1 as a reference and found GSyV-1-specific contigs in six of the libraries (5_ZE, 6_ZG, 12_KSZ, 14_AD, 17_LB and 18_AS) (Supplementary Table 7). RT-PCR test for GSyV-1 was positive for five out of these six libraries, and in additional nine libraries (Supplementary Fig. 6), indicating that GSyV-1 was present in the rootstock vineyards. Because of this contradiction we tested different genotypes at the vineyards using RT-PCR (Supplementary Fig. 8). Our summarized results show that only 4_BH and 19_TB were free from GSyV-1. As we found different results when using different references, the false-negative results of small RNA HTS may have been due not to small RNA HTS but to the shortage of enough references during bioinformatics analysis. PCR products of the library pools were sequenced and the sequences were deposited into GenBank MK975806 MK975819 (Supplementary Table 5). Their phylogenetic analysis showed that these strains were distantly related (Fig. 3), explaining why their identification by small RNA HTS using different references led to different results. Rootstock vineyards were not homogenously infected. Some genotypes at the same vineyard were infected while other were not (Supplementary Fig. 8, Supplementary Table 9 and Table 2) indicating that GSyV-1 infection could originate from the infected material used for planting and not on site. To correlate the infection to the particular genotype we have found that $81.8 \%$ of the total $5 \mathrm{C}$ individuals and $77.8 \%$ of $5 \mathrm{BB}$ individuals were infected, while only $26.7 \%$ of individuals of Fercal, the most widespread genotype, showed the presence of GSyV-1 (Table 2).

We found GPGV-specific contigs and RT-PCR product in all of the libraries, showing that this virus is widespread in the country (Supplementary Table 7 and Supplementary Fig. 6). This finding is in line with the results of our previous survey, where we detected the presence of GPGV in all of the surveyed vineyards in the country (Czotter et al. 2018b). Although GPGV was present in all of the vineyards, similarly to the GSyV-1 infections, not every genotype was infected (Supplementary Fig. 9, Supplementary Table 9 and Table 2). In total, $60 \%$ of Fercal individuals, $54 \%$ of $5 \mathrm{C}$ individuals, $55 \%$ of $5 \mathrm{BB}$ individuals, $71 \%$ of S.O. 4 individuals, and $50 \%$ of Ruggeri and 125AA individuals were infected by GPGV (Table 2).

Similar to GSyV-1 infection, GPGV infection is widespread in Europe. A latent variant of the virus was found throughout Slovakia, the Czech Republic and Hungary (Czotter et al. 2018b; Eichmeier et al. 2018; Glasa et al. 2014). However, it is still not clear which sequence alterations are the main determinants of the disease; symptomatic variants cluster together and encode a six-amino-acid-shorter movement protein than the asymptomatic variants (Saldarelli et al. 2015). During our previous survey, we did not detect the symptomatic variant in the surveyed vineyards. However, in a different location, Csokako, we found one Pinot gris plant showing the typical symptoms of grapevine leaf mottling and deformation disease (Fig. 4). As this was the first symptomatic plant that we found in Hungary, we sequenced its amplified region (HuCSK9s: MK953676). We also sampled and sequenced GPGV from the neighbouring asymptomatic plant (HUCSK8: MK953677).

HuCSK9s containing the internal stop codon clustered with the published symptomatic variants (Saldarelli et al. 2015) while HUCSK8 was more similar to the published asymptomatic variants (Fig. 5).

Sequences of the GPGV variants from different rootstock genotypes and vineyards (GenBank MK904611 - 


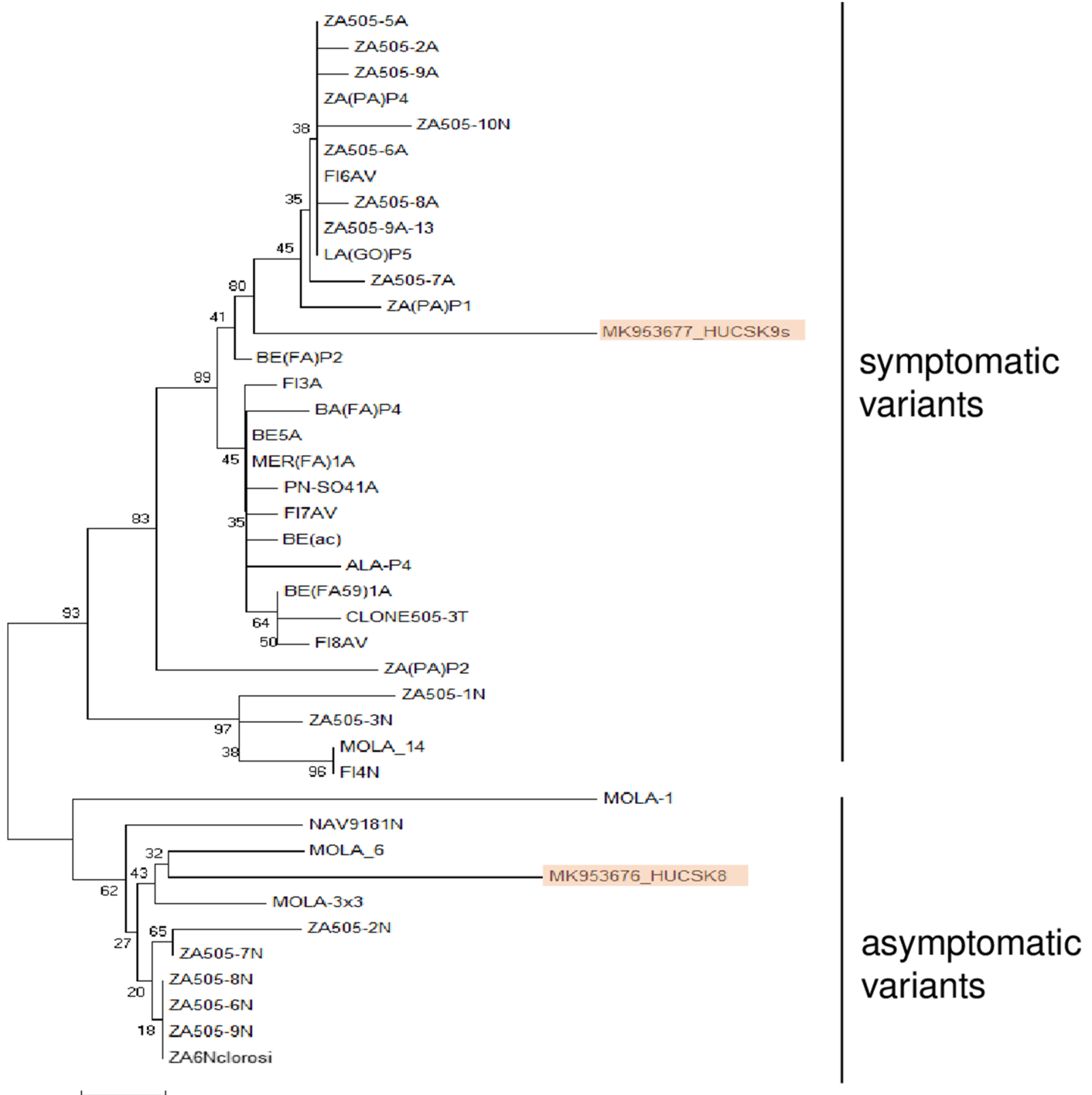

Fig. 5 Phylogenetic analysis of the symptomatic variant (HUCSK9s - MK953676) and asymptomatic variant (HUCSK8 - MK953677) of GPGV present at a Pinot gris vineyards at Csokako together with other symptomatic and asymptomatic

MK904647, Supplementary Table 5) indicated that this symptomatic variant was present in different locations (12_KSZ, 14_AD, 17_LB and 18_AS) (Table 2 and Supplementary Table $\overline{5}$ ), although the latter three are geographically close to each other. Phylogenetic analysis showed that these variants not only clustered together
GPGV variants. The tree was constructed using neighbour-joining method of MEGA7. GeneBank accession numbers of the GPGV variants are available in Saldarelli et al. 2015

but also clustered with the symptomatic variant from Csokako and Italy (Fig. 6). The sensitivities of cultivars to the symptomatic variant of GPGV causing "grapevine leaf mottling and deformation" (GLMD) are different (Saldarelli et al. 2015). GPGV variants associated with disease are Pinot gris, Traminer, Tocai (Friulano) 


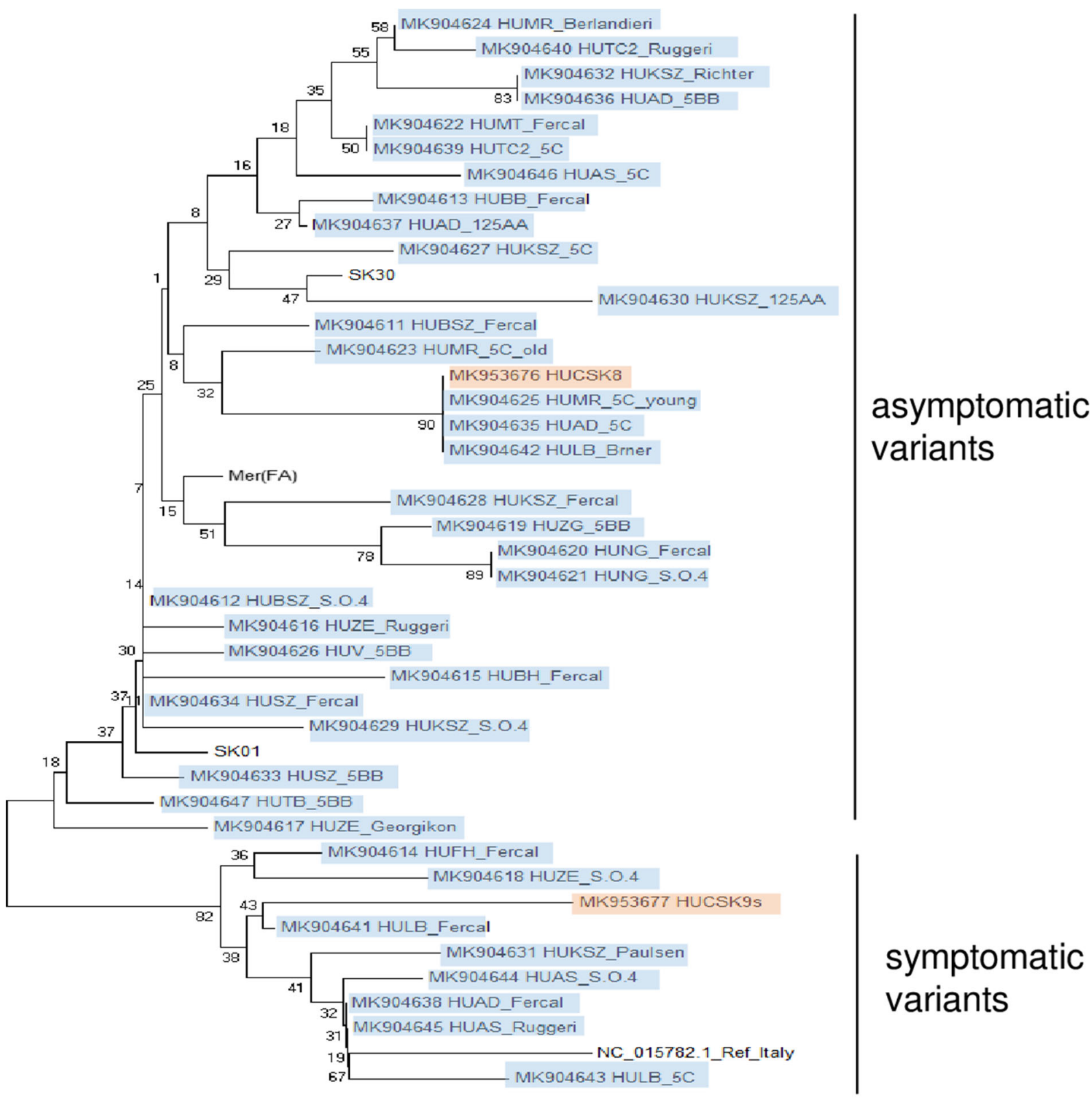

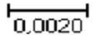

Fig. 6 Phylogenetic analysis of GPGV strains originated from different rootstock genotypes at different vineyards (MK904611 MK904647) together with the sequence of the symptomatic and

and Glera, in which uneven ripening causes economic losses in Northern Italian Prosecco production (Bertazzon et al. 2017). Moreover, last year, it was found to cause GLMD in France on two additional cultivars: Pinot Meunier and Grenache (RenaultSpilmont et al. 2018). We have found the symptomatic variant of the virus on symptomless rootstocks asymptomatic variants originating from Csokako. The tree was constructed using neighbour-joining method of MEGA7

suggesting that GPGV infection is latent in rootstocks, but without further investigations it cannot be ruled out that presence of the symptoms depends on the rootstock genotypes. Tarquini and colleagues showed that the early periods of infection by asymptomatic and symptomatic strains were similar with both showing some recovery of the phenotype later (Tarquini et al. 2019) 
and a statistically significantly higher virus titre was shown to correlate with the appearance of the symptoms (Bertazzon et al. 2017; Bianchi et al. 2015). We have found that in contrast to regulated viruses, currently non-regulated viruses were present in most of the investigated rootstock vineyards. Moreover, the genotypes were not equally infected, which suggested that, similar to our previous vineyard survey (Czotter et al. 2018b), the foundation stocks could be the source of virus infection.

\section{Conclusions}

Our virus diagnostic survey showed that grapevine rootstock vineyards are highly infected with non-regulated viruses and viroids. This finding highlights recent challenges that plant virologists face. Although HTS helps us to describe sequences of previously undescribed viruses, regulation of their presence will only be possible after their detailed characterization and possible risk analysis (Massart et al. 2017). Infection by a single virus or viroid could be latent or symptomless especially in the rootstocks, but combined infection could lead to diseases (Szychowski et al. 1995). The sensitivity of different cultivars to the viruses and to mixed infections may vary and this is not yet characterized in details, especially not for the recently described viruses. Moreover, the susceptibility of the rootstocks could lead to graft incompatibility, in turn causing a decline in young vineyards (Rowhani et al. 2017). The effect of mixed infections could be further altered by differences in climate, geographical location and cultivar, which are very difficult to predict.

Our work shows that non-regulated viruses can be very widespread, even in officially "clean" grapevine rootstock foundation stocks. Before official regulation of particular viruses, proper and careful risk assessment should be performed (Golino et al. 2017; Massart et al. 2017; Maree et al. 2018). However, the urgency and importance of these tasks should be highlighted, as the presence of these viruses at the grapevine rootstock vineyards indicates a new, uncontrolled site for virus distribution.

Acknowledgements We would like to acknowledge the valuable contributions of Anna Hegyi, Carmen Iliescu and the growers at the rootstock vineyards. We would also like to thank Balazs Zsolnay for helping us find the symptomatic variant of GPGV and Zoltan Havelda for his critical remarks. E.D. is a PhD student of the Doctoral School of Biological Sciences at Szent István University.

The authors would like to acknowledge the contribution of the COST Action FA 1407-DIVAS (Deep Investigation of VirusAssociated Sequences).

Funding information Open access funding provided by National Agricultural Research and Innovation Centre (NAIK). This research was funded by National Research, Development and Innovation Office (NKFIH) grant numbers: K119783 (E.V.) and K119287 (G.E.T.).

\section{Compliance with ethical standards}

Conflict of interest The authors declare that they have no conflict of interest.

Human participants and/or animals Not applicable.

Informed consent Not applicable.

Open Access This article is licensed under a Creative Commons Attribution 4.0 International License, which permits use, sharing, adaptation, distribution and reproduction in any medium or format, as long as you give appropriate credit to the original author(s) and the source, provide a link to the Creative Commons licence, and indicate if changes were made. The images or other third party material in this article are included in the article's Creative Commons licence, unless indicated otherwise in a credit line to the material. If material is not included in the article's Creative Commons licence and your intended use is not permitted by statutory regulation or exceeds the permitted use, you will need to obtain permission directly from the copyright holder. To view a copy of this licence, visit http://creativecommons.org/licenses/by/4.0/.

\section{References}

Bertazzon, N., Forte, V., Filippin, L., Causin, R., Maixner, M., \& Angelini, E. (2017). Association between genetic variability and titre of grapevine pinot gris virus with disease symptoms. Plant Pathology, 66, 949-959.

Bianchi, G. L., De Amicis, F., De Sabbata, L., Di Bernardo, N., Governatori, G., Nonino, F., et al. (2015). Occurrence of grapevine pinot gris virus in Friuli Venezia Giulia (Italy): Field monitoring and virus quantification by real-time RTPCR. EPPO Bulletin, 45, 22-32.

Boonham, N., Kreuze, J., Winter, S., van der Vlugt, R., Bergervoet, J., Tomlinson, J., \& Mumford, R. (2014). Methods in virus diagnostics: From ELISA to next generation sequencing. Virus Research, 186, 20-31.

Coetzee, B., Freeborough, M. J., Maree, H. J., Celton, J. M., Rees, D. J., \& Burger, J. T. (2010). Deep sequencing analysis of 
viruses infecting grapevines: Virome of a vineyard. Virology, 400, 157-163.

Czotter, N., Molnar, J., Pesti, R., Demian, E., Barath, D., Varga, T., et al. (2018a). Use of siRNAs for diagnosis of viruses associated to Woody plants in nurseries and stock collections. Methods in Molecular Biology, 1746, 115-130.

Czotter, N., Molnar, J., Szabó, E, Kocsis, L., Deak, T, Bisztray, GY et al (2015) First description of Grapevine Syrah virus 1 in vineyards of Hungary. Journal of Plant Pathology, 97(4)sup. https://doi.org/10.4454/JPP.V97I4SUP.022.

Czotter, N., Molnar, J., Szabó, E., Demian, E., Kontra, L., Baksa, I., et al. (2018b). NGS of virus-derived small RNAs as a diagnostic method used to determine Viromes of Hungarian vineyards. Frontiers in Microbiology, 9(122). https://doi. org/10.3389/fmicb.2018.00122.

Eichmeier, A., Kominkova, M., Kominek, P., \& Baranek, M. (2016). Comprehensive virus detection using next generation sequencing in grapevine vascular tissues of plants obtained from the wine regions of Bohemia and Moravia (Czech Republic). PLoS One, 11, e0167966. https://doi. org/10.1371/journal.pone.0167966.

Eichmeier, A., Penazova, E. and Muljukina, N. (2018) Survey of grapevine pinot gris virus in certified grapevine stocks in Ukraine. European Journal of Plant Pathology, 10.1007/ s10658-018-1497-5.

Elbeaino, T., Digiaro, M., Ghebremeskel, S., \& Martelli, G. P. (2012). Grapevine deformation virus: Completion of the sequence and evidence on its origin from recombination events between grapevine fanleaf virus and Arabis mosaic virus. Virus Research, 166, 136-140.

Felsenstein, J. (1985) Confidence limits on phylogenies: An approach using the bootstrap. Evolution; International Journal of Organic Evolution, 39, 783-791.

Gambino, G., Cuozzo, D., Fasoli, M., Pagliarani, C., Vitali, M., Boccacci, P., Pezzotti, M., \& Mannini, F. (2012). Coevolution between grapevine rupestris stem pittingassociated virus and Vitis vinifera L. leads to decreased defence responses and increased transcription of genes related to photosynthesis. Journal of Experimental Botany, 63, 5919-5933.

Gambino, G., Navarro, B., Torchetti, E., La Notte, P., Schneider, A., Mannini, F., et al. (2014). Survey on viroids infecting grapevine in Italy: Identification and characterization of Australian grapevine viroid and grapevine yellow speckle viroid 2. European Journal of Plant Pathology, 140, 199. https://doi.org/10.1007/s10658-014-0458-x.

Gambino, G., Perrone, I., \& Gribaudo, I. (2008). A rapid and effective method for RNA extraction from different tissues of grapevine and other woody plants. Phytochemical analysis $\therefore$ PCA, 19, 520-525.

Glasa, M., Predajna, L., Kominek, P., Nagyova, A., Candresse, T., \& Olmos, A. (2014). Molecular characterization of divergent grapevine pinot gris virus isolates and their detection in Slovak and Czech grapevines. Archives of Virology, 159, 2103-2107.

Glasa, M., Predajna, L., Soltys, K., Sabanadzovic, S., \& Olmos, A. (2015). Detection and molecular characterisation of grapevine Syrah virus-1 isolates from Central Europe. Virus Genes, $51,112-121$.

Golino, D. A., Fuchs, M., Al Rwahnih, M., Farrar, K., Schmidt, A., \& Martelli, G. P. (2017). Regulatory aspects of grape viruses and virus diseases: Certification, quarantine, and harmonization. In B. Meng, G. Martelli, D. Golino, \& M. Fuchs (Eds.), Grapevine viruses: Molecular biology, diagnostics and management (pp. 581-598). Cham: Springer.

Jukes, T. H. and Cantor, C. R. (1969) CHAPTER 24 - evolution of protein molecules. In: Mammalian protein metabolism. (Munro, H. N., ed.). Academic press, pp. 21-132.

Kumar, S., Stecher, G., \& Tamura, K. (2016). MEGA7: Molecular evolutionary genetics analysis version 7.0 for bigger datasets. Molecular Biology and Evolution, 33, 1870-1874.

Laucou, V., Boursiquot, J.-M., Lacombe, T., \& Bordenave, L. (2008). Parentage of grapevine rootstock 'Fercal' finally elucidated. Vitis, 47(3), 163-167.

Marasco, R., Rolli, E., Fusi, M., Michoud, G., \& Daffonchio, D. (2018). Grapevine rootstocks shape underground bacterial microbiome and networking but not potential functionality. Microbiome, 6, 3. https://doi.org/10.1186/s40168-017-03912.

Maree, H. J., Fox, A., Al Rwahnih, M., Boonham, N., \& Candresse, T. (2018). Application of HTS for routine plant virus diagnostics: State of the art and challenges. Frontiers in Plant Science, 9. https://doi.org/10.3389/fpls.2018.01082.

Martelli, J.P. (2018) Where grapevine virology is heading to. In Proceedings of the 19th Congress of ICVG (April 2018, Santiago, Chile).

Massart, S., Candresse, T., Gil, J., Lacomme, C., Predajna, L., Ravnikar, M., et al. (2017). A framework for the evaluation of biosecurity, commercial, regulatory, and scientific impacts of plant viruses and Viroids identified by NGS technologies. Frontiers in Microbiology, 8(45). https://doi.org/10.3389 /fmicb.2017.00045.

Massart, S., Chiumenti, M., De Jonghe, K., Glover, R., Haegeman, A., Koloniuk, I., et al. (2019). Virus detection by highthroughput sequencing of small RNAs: Large-scale performance testing of sequence analysis strategies. Phytopathology, 109, 488-497.

Massart, S., Olmos, A., Jijakli, H., \& Candresse, T. (2014). Current impact and future directions of high throughput sequencing in plant virus diagnostics. Virus Research, 188, 90-96.

Meng, B., Rebelo, A. R., \& Fisher, H. (2006). Genetic diversity analyses of grapevine Rupestris stem pitting-associated virus reveal distinct population structures in scion versus rootstock varieties. The Journal of General Virology, 87, 1725-1733.

Ollat, N., Bordenave, L., Tandonnet, J. P., Boursiquot, J. M. and Marguerit, E. (2016) Grapevine rootstocks: Origins and perspectives. International Society for Horticultural Science (ISHS), Leuven, Belgium, pp. 11-22.

Poczai, P., Hyvönen, J., Taller, J., Jahnke, G., \& Kocsis, L. (2013). Phylogenetic analyses of Teleki grapevine rootstocks using three chloroplast DNA markers. Plant Molecular Biology Reporter, 31, 371-386.

Renault-Spilmont, A.-S., Sevin Preyre, A.-F., Jérémy, G., Beuve, M., Alliaume, A., Marais, A., et al. (2018) Occurrence of grapevine pinot gris virus (GPGV) and grapevine leaf mottling and deformation (GLMD) syndrome in France: Genetic diversity and field monitoring in diverse viticulture areas. Proceedings of the 19th Congress of ICVG, Santiago, Chile, April 9-12. 
Roossinck, M. J., Martin, D. P., \& Roumagnac, P. (2015). Plant virus Metagenomics: Advances in virus discovery. Phytopathology, 105, 716-727.

Rowhani, A., Uyemoto, J. K., Golino, D. A., Daubert, S. D., \& Al Rwahnih, M. (2017). Viruses involved in graft incompatibility and decline. In B. Meng, G. Martelli, D. Golino, \& M. Fuchs (Eds.), Grapevine viruses: Molecular biology, diagnostics and management (pp. 289-302). Cham: Springer.

Saitou, N., \& Nei, M. (1987). The neighbor-joining method: A new method for reconstructing phylogenetic trees. Molecular Biology and Evolution, 4, 406-425.

Saldarelli, P., Giampetruzzi, A., Morelli, M., Malossini, U., Pirolo, C., Bianchedi, P., \& Gualandri, V. (2015). Genetic variability of grapevine pinot gris virus and its association with grapevine leaf mottling and deformation. Phytopathology, 105, 555-563.

Szychowski, J. A., McKenry, M. V., Walker, M. A., Wolpert, J. A., Credi, R., \& Semancik, J. S. (1995). The vein-banding disease syndrome: A synergistic reaction between grapevine viroids and fanleaf virus. Vitis, 34, 229-232.

Tarquini, G., Zaina, G., Ermacora, P., De Amicis, F., FrancoOrozco, B., Loi, N., et al. (2019). Agroinoculation of grapevine pinot Gris virus in tobacco and grapevine provides insights on viral pathogenesis. PLoS One, 14, e0214010.

Vigne, E., Marmonier, A., \& Fuchs, M. (2008). Multiple interspecies recombination events within RNA2 of grapevine fanleaf virus and Arabis mosaic virus. Archives of Virology, 153, 1771-1776. 